\title{
Prospects in the utilization of assisted reproductive technologies (ART) towards improved cattle production in Nigeria
}

\author{
Oguejiofor, C. F.
}

Department of Veterinary Obstetrics and Reproductive Diseases, Faculty of Veterinary Medicine, University of Nigeria, Nsukka 410001, Nigeria

Corresponding author: chike.oguejiofor@unn.edu.ng; +2348038993103

\section{Abstract}

Cattle production and the beef and dairy industry are important sources of financial revenue for the government and the individual farmers and employees involved in livestock husbandry. Nigeria has a huge potential for cattle production but sadly this has been poorly developed. The estimated national cattle population of 19 million is grossly inadequate in meeting the national human demand for meat, milk and other cattle products or in contributing to the gross domestic product. The low cattle productivity is partly attributable to the poor utilization of assisted reproductive technologies (ART) in dairy and beef cattle breeding and production. These technologies generally include oestrus synchronization, artificial insemination (AI), multiple-ovulation and embryo transfer (MOET), in vitro fertilization (IVF), sex determination, cloning and genetic engineering. ART have been applied extensively in the yearly production of millions of cattle in many developed and developing countries worldwide. This review highlights the applications and potentials of ART in cattle production and suggests how stakeholders in the Nigerian cattle industry can exploit these potentials. It is clear that the utilization of ART will enhance national livestock productivity so that Nigeria can feed her growing population and possibly increase her foreign exchange earnings by becoming a livestock-exporting country.

Keywords: assisted reproductive technologies, cattle production

\section{Introduction}

Nigeria has a current estimated human population of 198 million based on figures released by the population commission (National Population Commission, 2019). On the other hand, the recent livestock survey in Nigeria reported an estimated national cattle population of 19 million (National Agriculture Sample Survey, 2011). This is considered to be grossly inadequate in meeting the national human demand for meat, milk and other cattle products or in contributing to the gross domestic product (GDP). For instance, Nigeria's production of 0.6 million tons of milk per annum is comparatively one of the lowest in the world. This meets about 34\% of the estimated annual milk consumption of 1.7 million tons. Consequently, Nigeria has to spend an average of 480 million US Dollars on the importation of milk annually
(PricewaterhouseCoopers Report, 2017). Furthermore, the bureau of statistics reported that about $63 \%$ of Nigerians live below the poverty line (National Bureau of Statistics, 2016). Therefore, the low availability and high cost of livestock and animal products means that many Nigerians are unable to meet their minimum daily animal protein intake. Cattle production and the beef and dairy industry are important sources of financial revenue for the government and the individual farmers and employees involved in livestock husbandry. The cow has a limited reproductive lifespan. Therefore, high reproductive efficiency is essential for profitable cattle production. This is important for the production of replacement animals in the herd and calves which are sold to generate income for the farmer. Importantly, regular calf production is vital 


\section{Assisted reproductive technologies in cattle production}

to promote lactogenesis and to sustain milk production in dairy cows. To obtain these optimal results, the dairy cow has to conceive by three months after calving and deliver normal calves at regular intervals of about 365 days (Opsomer et al., 1998, Gates, 2013). Moreover, the utilization of cattle with high genetic potential (e.g. high feed conversion rate and high milk production) and the application of biotechnology have been globally recognized to significantly improve cattle breeding and the productivity of both beef and dairy cattle.

In Nigeria, poor nutrition, prevalence of cattle diseases, and the practice of nomadic pastoralism have been associated with low cattle productivity (Ducrotoy et al., 2016; PricewaterhouseCoopers Report, 2017). Furthermore, more than $99 \%$ of dairy cattle reared in Nigeria are the local indigenous breeds such as Bunaji, Rahaji and Sokoto Gudali whereas foreign breeds including Friesians, Jerseys and Brown Swiss, and cross breeds account for less than $1 \%$ (PricewaterhouseCoopers Report, 2017). Although the local breeds are genetically adapted to the tropical environment (Mwai et al., 2015), they produce far less milk than their foreign counterparts which has been attributed to genetic composition, and to some extent, management practices by dairy cattle farmers (Saleh et al., 2016). For instance, the average litres of milk produced per day was 30.15 and 1.57 for the Friesian and Bunaji breeds, respectively; but increased to 22.54 in Friesian-Bunaji crossbreds (Saleh et al., 2016).

The low cattle genetic potential and productivity is worsened by poor use of modern reproductive techniques, and the lack of planned and selective breeding for improved genetic potential and maximal productivity. Instead, there is indiscriminate breeding in cattle herds resulting in decreased reproductive potentials and the spread of diseases. Moreover, the slaughter of reproductively active female cattle (pregnant and cyclic cows) for food is rampant in Nigeria. This consequently leads to reproductive wastage, decreased cattle productivity, and significant financial losses in Nigeria (Alhaji, 2011; Ngbede et al., 2012; Akpabio and Babalola, 2014). Although many factors are associated with this reproductive wastage, limited veterinary and extension services in rural areas, and the lack of technology for proper analysis and identification of the reproductive status of cows prior to slaughter are major contributory factors (Fayemi and Muchenje, 2013). Therefore, it is overdue for an increase in the exploitation of modern methods of animal breeding and reproduction, if ever Nigeria hopes to overcome her shortcomings in cattle and other livestock productivity.

\section{Assisted reproductive technologies (ART)}

Assisted reproductive technologies (ART) are applied extensively in many parts of the world in humans and animals to advance our knowledge of reproductive processes and to promote reproductive efficiency. In livestock production, these technologies generally include oestrus synchronization, artificial insemination (AI), multipleovulation and embryo transfer (MOET), in vitro fertilization (IVF), sex determination, cloning and genetic engineering (Ball and Peters, 2004). These are powerful technologies capable of enhancing productivity, and when combined with bioinformatics will provide more impact in the future of animal production (Sejian et al., 2010). The cow is typically monotocous with an average gestation length of 40 weeks and therefore a relatively long generation interval. If there is no intervention, the rate at which a particularly desirable cow can be used to improve the genetic status of a herd is slow (Chakravarthi and Sri Balaji, 2010). Hence 


\section{Oguejiofor}

ARTs are particularly useful in this species because of the low reproductive rates and long generation intervals. In the cattle industry, ARTs were initially developed to increase the production of calves from parent cattle with high genetic potentials, but now offer many opportunities for beef and dairy cattle production.

\section{Oestrus synchronization}

Synchronization of oestrus involves the use of pharmacologic means to control oestrus and ovulation in farm animals. Thus female animals are made to undergo oestrus (ovulation) at a predetermined, convenient time, rather than when it would have occurred naturally. Generally, the techniques are based on either the artificial induction of premature luteolysis using luteolytic agents (e.g. prostaglandin F2 alpha or its analogues), or the administration of progestagens to temporarily suppress ovarian activity. Synchronization offers several advantages and facilitates the maximal and batch managements of AI and calving in cattle herds, thereby increasing productivity and decreasing costs in dairy and beef cattle production ( Pineda, 2003 ). Synchronization may offer some advantages in shortening the calving to conception interval, and thus the calving interval and possibly the calving season, particularly in beef herds. Accurate detection of oestrus is critical to achieving high pregnancy rates particularly in large cattle herds. Hence, oestrus synchronization offers another strategy to circumvent the critical problem of oestrus detection(Paul et al., 2015).

\section{Artificial insemination (AI)}

Artificial insemination has been utilized worldwide for more than 50 years. It is still the predominant technology applied for the improvement of reproductive efficiency and productivity in cattle through progeny testing and genetic improvement
(Chakravarthi and Sri Balaji, 2010). AI is the introduction of live spermatozoa into the genital tract of the female to cause fertilization by means other than natural mating. Semen from bulls can be extended and preserved at $4-5{ }^{\circ} \mathrm{C}$ for a few days or frozen in plastic straws in liquid nitrogen at $-196^{\circ} \mathrm{C}$ for years or decades. Semen from a few high-performance bulls can then be used to breed large number of cows leading to rapid genetic improvement and dissemination of new breeds within cattle populations (Ball and Peters, 2004). Movement of preserved semen instead of live bulls would also improve trade, reduce production cost and also decrease the spread of cattle diseases usually transmitted by direct contact between cattle. The use of AI also prevents the rearing of bulls that involve added cost along with the possibility of causing injury or death to farmers or staff. Controlling and recording the time of AI helps to avoid indiscriminate mating (often observed in natural mating), thereby facilitating proper farm recordkeeping and fertility management.

\section{Multiple ovulation and embryo transfer (MOET)}

The concept of MOET was introduced in 1987 and showed how MOET programmes could improve genetic gains by increasing selection intensity and reducing generation intervals (Smith, 1988). Multiple-ovulation (superovulation) is a pharmacologic technique applied to increase the number of oocytes released at ovulation, usually by 2 to $10 \mathrm{fold}$, thereby increasing the potential number of embryos. On the other hand, embryo transfer (ET) refers to the techniques by which embryos are collected from a female (donor) and transferred into the uterus of another female (recipient) where they develop to term. Typically, a cow ovulates a single oocyte during each reproductive cycle, and therefore may produce only 8 to 12 calves in her 


\section{Assisted reproductive technologies in cattle production}

reproductive lifetime. However, utilizing the technology for MOET, it is possible to obtain 30 to 40 calves from a single cow over a period of a year (Pineda, 2003). Through MOET, the numbers of imported highly valuable and scarce cattle breeds could be multiplied rapidly, leading to increased genetic improvement of cattle populations (Thomasen et al., 2016). Highly valued cows that are injured or too old to carry normal pregnancy could also be made to continue producing calves via MOET, rather than these animals being culled or sold for slaughter. Natural twinning ranges from $1-2 \%$ in beef cattle, but the efficiency of beef production could also be increased in intensively managed farms by inducing twinning using MOET. This technology also offers commercial advantage to farmers via a lower cost of importation of cryopreserved embryos compared to live cattle (Ball and Peters, 2004).

\section{In vitrofertilization (IVF)}

In vitro fertilization (IVF) is a technology via which oocytes are matured and fertilized outside of the female (in the laboratory). The method is also called in vitro embryo production. The resulting embryos are then transferred back to the same or different females for development. Mature oocytes can be collected by flushing the oviducts shortly after ovulation. Alternatively, immature oocytes can be obtained from abattoir ovaries or by aspiration of pre-ovulatory follicles using ovum pick up (OPU) from live cows. These oocytes must be cultured in vitro for 24 hours in sterile medium to allow for nuclear maturation prior to fertilization. Following in vitro maturation of oocytes, spermatozoa must also be capacitated using a capacitation medium (or alternatively by using ejaculated sperm) before they are capable of fertilizing the oocyte (Ball and Peters, 2004). The technology offers the potential for large numbers of in vitro produced embryos together with exciting opportunities for other technologies in cattle reproduction such as sex determination, cloning, genetic engineering and embryo transfer.

\section{Sex determination}

This technology is useful when calves of a particular sex are considered to be more valuable than those of the opposite sex. For instance, dairy farmers would prefer most of their calves to be female (replacement heifers for the milking herd) whereas beef farmers would prefer bull calves for their higher body mass and beef production potential. Sex could be determined either by semen sexing or embryo sexing. The presence of $\mathrm{Y}$ chromosome determines male offspring in mammals. In cattle, the Xbearing sperm contain 3.8\% more DNA than the Y-bearing sperm. Thus, sperm can be sorted using specific dye (Hoechst 33342) that binds to DNA and a flow cytometer/cell sorter. Embryos can also be sexed using several techniques including chromosome analysis (karyotyping), immunology, DNA analysis and detection of metabolic differences (Ball and Peters, 2004). Sexed semen could be applied in farms to inseminate cows with the aim of producing calves of the required sex, or for the fertilization of oocytes in vitro to produce embryos of the required sex. Sexed embryos could also be transferred to recipient cows to produce calves of the required sex (Pellegrino et al., 2016).

\section{Cloning and nuclear transfer}

These technologies involve cloning by embryo splitting to produce identical twins, triplets and quadruplets or the use of nuclear transfer to produce large numbers of genetically-identical or cloned cattle. In the nuclear transfer technique, the nuclei from either a blastomere (from early-stage embryos) or a somatic cell (other body cells) are fused individually to enucleated 


\section{Oguejiofor}

oocytes. The resulting zygotes are then cultured and transferred to recipient cows for development to term. Interestingly, this technique has attracted much international attention since 1996 when the first mammal (the sheep, Dolly) was cloned (Wilmut et al., 1997) followed later by cloning in cattle (Kato et al., 1998). With cloning technology, it is possible to exceed pregnancy rates of $100 \%$ in cattle farms. It also offers the potential for the production of large numbers of genetically-superior cattle to drive increased dairy and beef production (Pineda, 2003). For instance, it would normally require 78 months to reach production flock status in cows, but this can be achieved within 33 months with the nuclear transfer technology (Sejian et al., 2010). The success rate for propagating animals by nuclear transfer is expected to increase along with a reduction in the cost as newer methods are developed in the technology.

\section{Genetic engineering}

Transgenic livestock (pigs and sheep) were produced for the first time in 1985 (Hammer et al., 1985). This technology involves transferring a selected gene into an embryo so that the resulting offspring carry and express that gene later in life. Animals that carry a copy of a desired foreign gene are referred to as being transgenic (Pineda, 2003; Carlson and Lancto, 2016). Generally, transgenic technologies utilize embryo-mediated or cell-mediated genetic modification to generate an entire animal. In recent years, new technologies referred to as "gene editing" have also been added to the molecular tool box for genetic engineering of various organisms. Efficient and robust protocols are now available for producing sheep, goats, pigs, cattle and other species in which specific genes have been targeted for editing (Laible, 2018). The technology has been applied to improve different aspects of animal production. In cattle, these include the enhancement of milk quality, muscle yield, disease resistance (mastitis, tuberculosis), or improved welfare such as the production of hornless dairy cattle (Wu et al., 2015; Carlson and Lancto, 2016; Van Eenennaam, 2017). Nevertheless, the application of genetic engineering in livestock production has been limited by several significant factors. These include the cost of large animals, long generation times, and most importantly, legal, ethical and public health concerns and considerations (Laible, 2018). However, it is likely some of the newer technologies involving gene editing will become more acceptable particularly in the face of the increasing global animal protein demands and food insecurity. Already, the first genetically engineered salmon has been approved for sale as food by regulatory agencies in the US and Canada (Waltz, 2017). It is likely that other international agencies will begin to reconsider regulatory gridlocks on animal products from genetic engineering. In Africa, and particularly Nigeria, genetic engineering of bovine embryos may offer opportunities for the production of cattle that retain the genetic predisposition to hardiness, adaptation to the tropical environment (e.g. heat stress) and tolerance to tropical diseases (e.g. trypanosomosis) while incorporating genetic potential for rapid growth and increased milk and beef production (Mwai et al., 2015).

\section{Potential interventions}

There has been a significant increase in the utilization of ART, particularly AI and MOET, in the production of millions of cattle in many developed and developing countries worldwide. This has led to a tremendous increase in both dairy and beef cattle production in several countries such as the United States and Brazil. In Nigeria, AI has been routinely performed since 1978 at the national animal production research 


\section{Assisted reproductive technologies in cattle production}

institute (NAPRI), Zaria. Other interests include the monitoring of reproductive hormones and the improvement of oestrus synchronisation and heat detection. Crossbreeding of the indigenous breeds of cattle with the exotic breeds is also on-going in an effort to upgrade their traits for beef production. Efforts have also been made to improve the milk productivity of indigenous cattle through crossbreeding with exotic cattle (Friesian) to produce crossbred cows (Friesian-Bunaji) with a genetic potential for increased milk yield per day. Apart from NAPRI, AI is also performed in a few private commercial cattle farms. Unfortunately, these efforts impact a small proportion of cattle population in Nigeria. A recent study in northern Nigeria also revealed poor extension contact among dairy farmers, which blocks farmers from access to sources of improved dairy cattle technologies (Saleh et al., 2016). Tertiary institutions in Nigeria also present platforms for the utilization of ART in research that can improve animal reproduction and productivity. Many of these institutions have made considerable efforts in some areas of animal production, and in the treatment of reproductive diseases. Regrettably, there is a low potential for the application of ART, partly due to the absence of a number of equipment and facilities but also due to shortage of human skill or training.

Clearly, an intensive application of ART will assist in the improvement of reproductive efficiency and productivity in dairy and beef cattle farming in Nigeria through several approaches. Public and private tertiary institutions should be adequately funded and provided with modern research facilities, laboratories and equipment. Skills in ARTs should be incorporated and exploited in both teaching and research in veterinary and animal science institutions. There should be intensive and productive research collaboration between veterinarians, animal scientists, zoologists, reproductive physiologists, geneticists, embryologists, cell biologists and molecular biologists. Subsequent research findings should also be utilized productively by the stakeholders in the cattle industry (tertiary institutions, government agencies, and commercial cattle industries and cattle farmers) to improve cattle productivity. This includes proper classification and dissemination of improved beef and dairy cattle breeds to cattle producers. In addition, there should be continual provision of adequate trainings, workshops and extension services in the use of ART to both the public and private sector participants in the cattle industry. Finally, the Nigerian government should discourage nomadic pastoralism with its attendant human conflict and threat to national stability, while encouraging cattle ranching and the application of ART in cattle production.

In conclusion, it is important to note that whilst the focus here is on cattle, the principles and skills of ART are equally relevant to other livestock and animal species including sheep, goat, pig, horse, dog, cat, poultry, fish and wildlife. Globally, there is an intensive and increasing competition on the application of new technologies that will shape the future of animal breeding and production. This had led to massive global economic activities and international movement of products (e.g. semen, embryo and cattle breeds) targeted towards increased beef and dairy cattle production. It is important that Nigeria is not left behind. Nigeria has a huge potential for cattle and other livestock production but sadly this has been poorly developed. It is clear that the utilization of ART will enhance national livestock productivity so that Nigeria can feed her 
growing population and possibly increase her foreign exchange earnings by becoming a livestock-exporting country.

\section{References}

Akpabio, U. and Babalola, S. A. 2014. Incidence of foetal wastage and its economic implications in cattle slaughtered at Abak slaughter house Abak, Akwa-Ibom State. Journal of Reproduction and Infertility, 5:65-68.

Alhaji, N. B. 2011. Prevalence and economic implications of calf foetal wastage in an abattoir in Northcentral Nigeria. Tropical Animal Health and Production, 43:587-590.

Ball, P. J. and Peters, A. R. 2004. Reproductive biotechnologies. In: Reproduction in cattle. Third ed. Oxford, UK: Blackwell Publishing Ltd. p. 191-214.

Carlson, D. F. and Lancto, C. A. 2016. Production of hornless dairy cattle from genome-edited cell lines. Nature Biotechnology, 34:479-82.

Chakravarthi, P. V. and Sri Balaji, N. 2010. Use of assisted reproductive technologies for livestock development. Veterinary World, $3: 238-240$.

Ducrotoy M. J., Majekodunmi A. O., Shaw, A. P. M., Bagulo, H., Musa, U. B., Bertu, W. J., Gusi, A. M., Ocholi, R. A., Bryssinckx, W. and Welburn, S. C. 2016. Fulani cattle productivity and management in the Kachia Grazing Reserve, Nigeria. Pastoralism: Research, Policy and Practice, 6:25.

Fayemi, P. O. and Muchenje, V. 2013. Maternal slaughter at abattoirs: history, causes, cases and the meat industry. SpringerPlus, 2:125.

Gates, M. C. 2013. Evaluating the reproductive performance of British beef and dairy herds using national cattle movement records. Veterinary Record, 173:499.

Hammer, R. E., Pursel, V. G., Rexroad, C. E. Jr, Wall, R. J., Bolt, D. J., Ebert, K. M., Palmiter, R. D. and Brinster, R. L. 1985. Production of transgenic rabbits, sheep and pigs by microinjection. Nature, 315:680-683.

Kato, Y., Tani, T., Sotomaru, Y., Kurokawa, K., Kato, J., Doguchi, H., Yasue, H. and Tsunoda, Y. 1998. Eight calves cloned from somatic cells of a single adult. Science, 282:2095-2098.

Laible G. 2018. Production of transgenic livestock: overview of transgenic technologies. In: Niemann, H., Wrenzycki, C. (eds.) Animal Biotechnology 2. Springer, Cham.

Mwai, O., Hanotte, O., Kwon, Y-J. and Cho, S. 2015. African indigenous cattle: unique genetic resources in a rapidly changing world. Asian Australasian Journal of Animal Science, 28:911-921.

National Agriculture Sample Survey (NASS). 2011. Collaborative survey by the National Bureau of Statistics (NBS) and Federal Ministry of Agriculture And Rural Development, Federal Republic of Nigeria. Accessed on 05 March 2018.

National Bureau of Statistics (NBS). 2016. Annual Abstract of Statistics, Volume 1. The Federal Republic of Nigeria; www.nigerianstat.gov.ng. Accessed on 05 March 2018.

National Population Commission (NPC). 2019. Federal Republic of Nigeria; www.population.gov.ng. Accessed on 14 January 2019.

Ngbede, E. O., Hena, S. A., Oguntoye, O. 
O., Tarhyel R. and Bulus C. 2012. Bovine foetal wastage and its economic implication: a six-year $(2003-2008)$ retrospective study in an abattoir in northwestern, Nigeria. Scientific Journal of Veterinary Advances, 1:42-46.

Opsomer, G., Coryn, M., Deluyker, H. and De Kruif, A. 1998. An analysis of ovarian dysfunction in high yielding dairy cows after calving based on progesterone profiles. Reproduction in Domestic Animals, 33:193-204.

Paul, A. K., Yoisungnern, T. and Bunaparte, N. 2015. Hormonal $\mathrm{treatment}$ and estru s synchronization in cows: A minireview. Journal of Advanced Veterinary and Animal Research, 2:10-17.

Pellegrino, C. A., Morotti, F., Untura, R. M., Pontes, J. H., Pellegrino, M. F., Campolina, J. P., Seneda, M. M., Barbosa, F. A. and Henry, M. 2016. Use of sexed sorted semen for fixed-time artificial insemination or fixed-time embryo transfer of in vitro-produced embryos in cattle. Theriogenology, 86:888-893.

Pineda, M. H. 2003. Embryo transfer in domestic animals. In: Pineda, M. H. (ed.) McDonald's Veterinary Endocrinology and Reproduction. Fifth ed. Ames, Iowa, USA: Iowa State Press. p. 547-571.

PricewaterhouseCoopers Report. 2017. Transforming Nigeria's Agricultural Value Chain: a case study of the Cocoa and Dairy

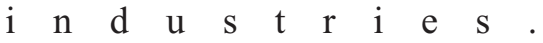
PricewaterhouseCoopers (PwC) $\mathrm{N}$ i g e ri a $\mathrm{n}$ L i m i t e d; www.pwc.com/ng. Accessed on 05 March 2018.

Saleh, M. K., Atala, T. K., Omokore, D. F.,
Ahmed, Ben, Ali, F. S. and Kajang, G. Y. 2016. Performance of improved dairy cattle technologies among farmers in northern Nigeria. Journal of Agricultural Extension, 20:1.

Sejian, V., Meenambigai, T.V., Chandirasegaran M. and Naqvi, S.M.K. 2010. Reproductive technology in farm animals: new facets and findings: a review. Journal of Biological Sciences, 10:686-700.

Smith, C. 1988. Genetic improvement of livestock using nucleus breeding units. World Animal Review, 65:210.

Thomasen, J. R., Willam, A., EggerDanner, C. and Sorensen, A. C. 2016. Reproductive technologies combine well with genomic selection in dairy breeding programs. Journal of Dairy Science, 99:1331-1340.

Van Eenennaam, A. L. 2017. Genetic modification of food animals. Current Opinion in Biotechnology, 44:27-34.

Waltz, E. 2017. First genetically engineered salmon sold in Canada. Nature, 548:148.

Wilmut, I., Schnieke, A. E., McWhir, J., Kind, A. J. and Campbell, K. H. 1997. Viable offspring derived from fetal and adult mammalian cells. Nature, 385:810-813.

Wu, H., Wang, Y., Zhang, Y., Yang, M., Lv, J., Liu, J., Zhang, Y. 2015. TALE nickase-mediated SP110 knockin endows cattle with increased resistance to tuberculosis. Proceedings of the National Academy of Sciences of the USA, 112:E1530-E1539.

Received: $28^{\text {th }}$ April, 2019 Accepted: $18^{\text {th }}$ December, 2019 